\title{
An avoidable transmission of HIV from mother to child
}

\author{
Tyler O’Bryan, Taj Jadavji MB, John Kim PhD, M. John Gill MB
}

Competing interests: None declared.

This article has been peer reviewed.

Correspondence to: Dr. M. John Gill, john.gill @albertahealthservices.ca

CMAJ 2011. DOI:10.1503 /cmaj.091137

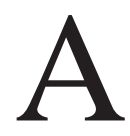

29-year-old married woman, an immisented to the Southern Alberta HIV Clinic at week 26 of pregnancy after receiving a positive test result from prenatal HIV screening. She had a university-level education, was fluent in English and agreed to start highly active antiretroviral therapy (HAART). At 28 weeks' gestation, the patient began taking zidovudine (300 $\mathrm{mg}$ twice daily), lamivudine (150 mg twice daily) and nelfinavir (1.25 g twice daily) both for her health and to reduce the risk of perinatal HIV transmission. ${ }^{1}$

During her pregnancy, the patient repeatedly reported consistent adherence to the HAART without adverse events. Her HIV viral loads measured with the NucliSens HIV-1 QT assay (bioMérieux, USA) and CD4 counts are shown in Table 1. Although the CD4 count remained at about $0.20 \times 10^{9} / \mathrm{L}$, the viral load remained undetectable.

While a patient at the HIV clinic, the woman had seven visits with her HIV specialist (who was also her child's pediatrician) and had numerous pharmacy, dietary and nursing consultations. The patient also regularly attended a separate high-risk pregnancy clinic for extra counselling before delivery.

During labour and delivery, the patient declined a cesarean section. She was given intravenous zidovudine at a loading dose of $2 \mathrm{mg}$ per kilogram of pregnancy weight infused over one hour, with hourly infusions of $1 \mathrm{mg} / \mathrm{kg}$ until the umbilical cord was clamped. Post partum, the baby was given zidovudine $(2 \mathrm{mg} / \mathrm{kg}$ orally grant from sub-Saharan Africa, pre-

\footnotetext{
- KEY POINTS

- Concern regarding confidentiality and social stigma may impair adherence to antiretroviral therapy.

- New biological diversity of HIV subtypes may cause unreliable results in HIV viral load testing.

- The social pressure for breastfeeding is significant in many communities.

- Recognizing and addressing these issues is critical for the optimal care of immigrants living with HIV.
}

every six hours) for six weeks.

The mother was strongly advised against breastfeeding to avoid the risk of HIV transmission to her child and was offered free formula to support this approach. Post partum, the mother received weekly home visits by a nurse from the high-risk pregnancy clinic for more counselling and medication adjustments for her infant. She reported mild depression but declined interventions. Slightly erratic attendance at the HIV clinic was attributed to family and child care issues. She reported ongoing adherence to the HAART and feeding with formula only.

At birth and at three and eight months of age, the child was found to be HIV-negative using polymerase chain reaction testing. At 12 months of age, the test results were indeterminate. Testing at 13 months showed that the baby had the same pansensitive HIV-1, group M, subtype G virus that the mother had.

\section{Discussion}

Three convergent circumstances may have led to HIV transmission from an immigrant mother to her child via breastfeeding, despite active medical care. The HAART regimen may not have been effective because of covert nonadherence related to lack of family support, stigma and fear of disclosure. The standard assay used to quantify HIV viral load failed to detect active viral replication, which would have alerted her physician to a potential problem. Despite the availability of free formula and the counselling against breastfeeding provided at both the HIV clinic and the high-risk pregnancy clinic, the mother may have breastfed her child because of family pressure and cultural expectations.

The documented risk of mother-child HIV transmission among patients receiving HAART with an undetectable viral load and in the absence of breastfeeding is less than $2 \% .^{2}$ Good adherence to HAART is essential to achieve an undetectable viral load. ${ }^{2}$ However, some viral subtypes may not be amplified adequately, which will lead to falsely low viral loads on test 
results..$^{3-5}$ Breastfeeding at the time of ongoing viral replication is well known to facilitate mother-child HIV transmission. ${ }^{6.7}$

\section{Quality-assurance investigation}

We conducted a quality-assurance investigation that retrospectively explored each aspect of our patient's care in depth.

\section{Pharmacy records}

The patient had always claimed good adherence to the HAART. ${ }^{2}$ Retrospective analysis of mean corpuscular volumes showed no elevation, which suggested that zidovudine may not have been taken. Analysis of a stored plasma sample, collected during a clinic visit when she had advised us of good adherence, failed to show the presence of nelfinavir. With the pharmacy's help, we compared the amount of HAART prescribed with the amount dispensed and calculated a maximal adherence of $63 \%$. When asked about this inconsistency, the patient advised us that the lack of her husband's support for her taking HAART, and her concern regarding accidental disclosure of her HIV status and possible stigma in her community, had contributed to her poor adherence.

\section{Viral load testing}

Viral load testing is the cornerstone of HIV care and is ideal for detecting treatment failure due to resistance or poor adherence. ${ }^{8}$ Detection of resistance or nonadherence allows health care providers to intervene and provide alternative treatment. Case reports have documented the occasional inability of several assays to quantify HIV viral loads adequately, which leads to incorrect, low measurements. ${ }^{3,4}$ Such difficulties are more frequently reported with non-B HIV subtypes, which often originate outside of North America and Europe. ${ }^{5}$ This association may be due to different sequences in the HIV gag gene that some assays use to amplify for quantitation. We tested stored plasma samples using a second assay (VERSANT HIV-1 RNA 3.0 [bDNA], Siemens Healthcare Diagnostics, USA) that targets a different area of the HIV genome (the pol gene). The results showed that our routine assay was not adequately quantifying a detectable viremia (Table 1).

\section{Breastfeeding records}

Breastfeeding is a well-documented means to transmit HIV. ${ }^{6,7}$ In some cultures, mothers are under substantial pressure to breastfeed as a demonstration of good motherhood. ${ }^{9}$ Hofmaan and colleagues found that, even though many mothers in sub-Saharan Africa knew the risks of HIV transmission via breastfeeding, most continued to breastfeed even when formula was safe and available. ${ }^{9}$ After an initial denial, our patient confirmed that, because of family pressure from those who were unaware of her HIV status and with her husband's encouragement, she had been breastfeeding. A retrospective review of the HIV clinic's records of dispensed free formula showed that the patient had declined the formula stating, "Family have been giving me lots of formula."

\section{Modifications to practice}

Since this situation, we have implemented several practice changes. Adherence records based on pharmacy refills and pickups are now entered into clinical charts to improve the likelihood of detecting poor adherence. Four different commercial viral load assays were tested to select the one most likely to provide uniform and reliable viral loads for our population with a large number of non-B HIV subtypes. ${ }^{10}$ Subtyping and genotyping of HIV in new patients is now used to identify patients who may need additional laboratory testing. The HIV clinic now reinforces better surveillance by staff of possible breastfeeding by women with cultural ties that strongly

Table 1: CD4 counts and HIV viral loads in a pregnant woman with HIV infection

\begin{tabular}{|lccc|}
\hline Collection of sample & $\begin{array}{c}\text { CD4 count, } \times 10^{9} / \mathrm{L} \\
\text { (\% of total } \\
\text { lymphocytes) }\end{array}$ & $\begin{array}{c}\text { Viral load using } \\
\text { NucliSens HIV-1 QT } \\
\text { assay, }{ }^{*} \text { copies/mL }\end{array}$ & $\begin{array}{c}\text { Viral load using VERSANT } \\
\text { HIV-1 RNA 3.0 assay, }{ }^{*} \\
\text { copies/mL [log }\end{array}$ \\
\hline 3 mo antepartum & $0.22(12)$ & $<40$ (undetectable) & 3580 [3.55] \\
\hline 1 mo antepartum & $0.25(12)$ & $<80$ (undetectable) & $-\dagger$ \\
\hline 8 mo postpartum & $0.14(7)$ & $<40$ (undetectable) & $4119[3.61]$ \\
\hline 12 mo postpartum & $0.25(10)$ & $-\dagger$ & $3331[3.52]$ \\
\hline 15 mo postpartum & $-\dagger$ & $-\dagger$ & $5480[3.74]$ \\
\hline 18 mo postpartum & $0.15 \quad(7)$ & $<50$ (undetectable) & $2279[3.36]$ \\
\hline $\begin{array}{l}\text { *Viral loads were measured with the use of stored plasma samples obtained on the specified dates. } \\
\text { tTesting not done. }\end{array}$ & & \\
\hline
\end{tabular}


encourage breastfeeding. Recognizing and addressing family pressures and cultural issues that may impede care is now a priority. As well, protocols are in place to check that the free formula is picked up by each patient.

\section{Conclusion}

Three convergent circumstances contributed to this unfortunate case of mother-child HIV transmission via breastfeeding. Adherence to HAART in this patient would likely have brought her viral load to undetectable levels, greatly reducing the risk of transmission. Had the standard assay used to measure the patient's viral load given accurate readings on a subtype $G$ virus, her physician would have been alerted earlier to the ongoing viral replication. Feeding with formula in lieu of breast milk would have eliminated this mode of transmission.

When caring for immigrant populations, physicians and other health care providers should consider the effects of biological differences in HIV subtypes on testing. In addition, stigma, denial, lack of family support and cultural expectations may lead to patient decisions with poor medical outcomes. ${ }^{11}$ Understanding and working with such issues will be of increasing importance in all developed countries with a growing population of immigrants with HIV infection. ${ }^{12}$

\section{References}

1. Bartlett JG, Gallant JE. Medical management of HIV infection. Baltimore (MD): Johns Hopkins Medicine Health Publishing Business Group; 2007. p. 116-7.

2. Panel on Treatment of HIV-Infected Pregnant Women and Prevention of Perinatal Transmission. Recommendations for use of antiretroviral drugs in pregnant HIV-infected women for maternal health and interventions to reduce perinatal HIV transmission in the United States. Available: http://aidsinfo .nih.gov/ContentFiles/PerinatalGL.pdf (accessed 2009 Feb. 28).

3. Geelen S, Lange J, Borleffs J, et al. Failure to detect a non-B HIV-1 subtype by the HIV-1 Amplicor Monitor test, version
1.5: a case of unexpected vertical transmission. AIDS 2003;17: $781-2$

4. Kim JE, Beckthold B, Chen Z, et al. Identification of a novel HIV type 1 subtype $\mathrm{H} / \mathrm{J}$ recombinant in Canada with discordant HIV viral load (RNA) values in three different commercial assays. AIDS Res Hum Retroviruses 2007;23:1309-13.

5. Drexler JF, Souza Luna LK, Pedroso C, et al. Rates and reasons for failure of commercial human immunodeficiency virus type 1 viral load assays in Brazil. J Clin Microbiol 2007;45:2061-3.

6. Colebunders R, Hodossy B, Burger D, et al. The effect of highly active antiretroviral treatment on viral load and antiretroviral drug levels in breast milk. AIDS 2005;19:1912-5.

7. Lehman DA, Chung MH, John-Stewart GC, et al. HIV-1 persists in breast milk cells despite antiretroviral treatment to prevent mother-to-child transmission. AIDS 2008;22:1475-85.

8. Panel on Antiretroviral Guidelines for Adults and Adolescents. Guidelines for the use of antiretroviral agents in HIV-1-infected adults and adolescents. Available: www.aidsinfo.nih.gov/Content Files/AdultandAdolescentGL.pdf (accessed 2009 Feb. 28).

9. Hofmann J, De Allegri M, Sarker M, et al. Breast milk as the "water that supports and preserves life" - socio-cultural constructions of breastfeeding and their implications for the prevention of mother to child transmission of HIV in sub-Saharan Africa. Health Policy 2009;89:322-8.

10. Church D, Gregson D, Lloyd T, et al. HIV-1 viral load multiassay comparison of the RealTime HIV-1, COBAS TaqMan 48 v. 1.0, Easy Q V1.2 and Versant V3.0 assays in a cohort of Canadian patients with diverse HIV subtype infections. $J$ Clin Microbiol. In press.

11. Thorsen VC, Sundby J, Martinson F. Potential initiators of HIVrelated stigmatization: ethical and programmatic challenges for PMTCT programs. Dev World Bioeth 2008;8:43-50.

12. Krentz H, Gill MJ. The five-year impact of an evolving global epidemic, changing migration patterns, and policy changes on a regional Canadian HIV population. Health Policy 2009;90: 296-302.

Affiliations: From the Southern Alberta HIV Clinic (O’Bryan, Jadavji, Gill), Calgary, Alta; and the National Laboratory for HIV Reference Services (Kim), Public Health Agency of Canada, Ottawa, Ont.

Contributors: All of the authors contributed substantially to the drafting or revising of the manuscript and approved the final version submitted for publication.

Acknowledgements: The authors thank Ms. Nancy Sheehan of the McGill University Health Centre and Université du Montréal for testing the antiretroviral drug level, Ms. Brenda Beckthold for organizing storage and repeat assays of the plasma samples, Ms. Jennifer Mihowich for repeat testing of samples with the VERSANT HIV-1 RNA 3.0 assay and Dr. Hartmut Krentz for providing invaluable comments on earlier drafts of the manuscript. 